\title{
O USO DE COMPETIÇÕES NA EDUCAÇÃO PROFISSIONAL: um estudo de caso no Senal-SP
}

\author{
The use of competitions in professional education: \\ a case study in Senai-SP
}

\section{El uso de competiciones en la educación profesional: un estudio de caso en el Senai-SP}

RESUMO As competições de educação profissional são torneios realizados por Instituições de Educação Profissional, envolvidas ou não com a organização do evento. A finalidade é avaliar os conhecimentos, habilidades e atitudes de participantes a partir de situações problema propostas por meio de projetos-teste que visam atingir os resultados esperados dentro dos padrões de qualidade estabelecidos pela instituição organizadora. Essa atividade pode ser utilizada como um instrumento para considerar o nível de excelência da formação profissional de docentes e discentes. É nesse contexto que o SENAI realiza periodicamente a Olimpíada do Conhecimento. Este artigo tem por objetivo apresentar as experiências relatadas pelos professores treinadores do SENAI-SP com relação às suas participações nas competições de Educação Profissional. A pesquisa tem enfoque qualitativo, por intermédio de pesquisa bibliográfica, documental e pesquisa de campo com professores treinadores. Os resultados sugerem que para o professor treinador a competição propicia atualização profissional, aperfeiçoamento de conhecimentos técnicos, desenvolvimento de capacidades de trabalho em equipe e construção de uma rede de relacionamento. Também propicia experiência única na vida de cada participante.

Palavras-chave: Educação Profissional. CompetiçÃo. SENAI-SP. OlimpíADA DO CONHECIMENTO. AVALIAÇÃO INSTITUCIONAL.

ABSTRACT Professional education competitions are tournaments held by and for Professional Education Institutions, whether or not they have been involved in its organization. The purpose is to evaluate the knowledge, skills and attitudes of participants from situations proposed problems through test projects that aim to achieve the expected results within the quality standards established by the organizing institution. They can be instruments used to assess the level of excellence of their professional training. It is in this context that SENAI periodically holds the Knowledge Olympics. This article aims to present the experiences reported by the SENAI-SP teacher's professors in relation to their participation in the Professional Education competitions. The resear-

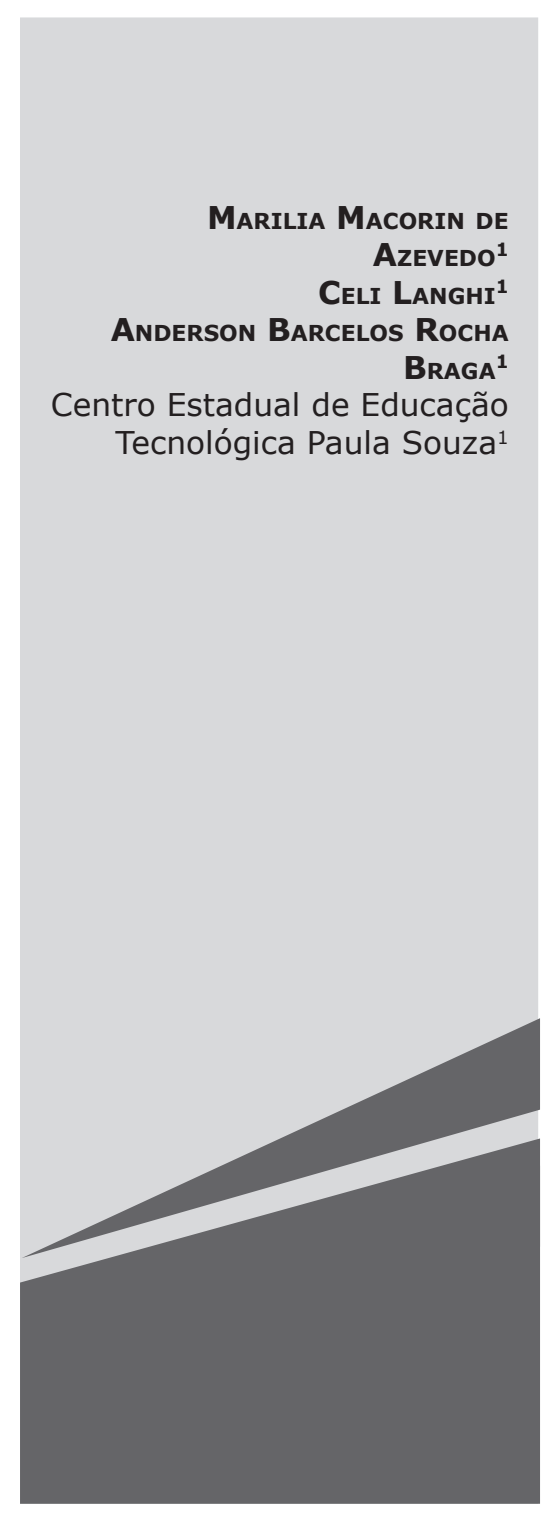


ch has a qualitative focus, through bibliographical research, documentary and field research with teacher's coaches. The results suggest that for the coach, the competition provides professional updating, improvement of technical knowledge, development of teamwork skills and building a network of relationships. It also provides unique experience in each participant's life.

KEYWORDS: PROFESSIONAL EDUCATION. COMPETITION. SENAI-SP. KNOWLEDGE OlYMPICS. INSTITUTIONAL EVALUATION.

RESUMEN Las competiciones de educación profesional son torneos realizados por Instituciones de Educación Profesional, involucradas o no con la organización del evento. La finalidad es evaluar los conocimientos, habilidades y actitudes de participantes a partir de situaciones problemáticas propuestas por medio de proyectos-test que apuntan a alcanzar los resultados esperados dentro de los estándares de calidad establecidos por la Institución organizadora. Pueden ser instrumentos utilizados para evaluar el nivel de excelencia de su formación profesional. Es en este contexto que el SENAI realiza periódicamente la Olimpiada del Conocimiento. Este artículo tiene por objetivo presentar las experiencias relatadas por los profesores entrenadores del SENAI-SP con relación a sus participaciones en las competencias de Educación Profesional. La investigación tiene enfoque cualitativo, por medio de investigación bibliográfica, documental e investigación de campo con profesores entrenadores. Los resultados sugieren que para el profesor entrenador la competencia propicia actualización profesional, perfeccionamiento de conocimientos técnicos, desarrollo de capacidades de trabajo en equipo y construcción de una red de relación. También ofrece experiencia única en la vida de cada participante.

Palabras Clave: Educación PROFESIONAL. LA COMPETÊNCIA. SENAI-SP. OLIMPIADA DEL CONOCIMIENTO. EVALUACIÓN INSTITUCIONAL.

\section{INTRODUÇ̃̃o}

As competições de Educação Profissional são torneios ou campeonatos, geralmente, realizados por Instituições de Educação Profissional e Tecnológica nacionais e internacionais. O Serviço Nacional de Aprendizagem Industrial - SENAI, o Serviço Nacional de Aprendizagem Comercial - SENAC e Institutos Federais são exemplos de instituições nacionais. As instituições internacionais como a WorldSkills International (WSI) e a Worl-
dSkills Americas (WSA) promovem as competições e congregam instituições de Educação Profissional de vários países que se filiam como membros, a fim de promoverem sua marca institucional por intermédio dos resultados obtidos por seus alunos e ex-alunos, sendo referência em seu meio de atuação na formação profissional e tecnológica. Os objetivos são avaliar conhecimentos, habilidades e atitudes face a situações problema dos projetos-teste a que os participantes são submetidos, em suas respectivas áreas tecnoló- 
gicas, tendo em vista o alcance de resultados esperados dentro de padrões de qualidade estabelecidos pela instituição organizadora da competição.

No Brasil, conforme aponta o site do SENAI, ${ }^{1}$ desde 2001 são reunidos os melhores alunos dos cursos de Educação Profissional do país para participar das Olimpíadas do Conhecimento. Nessa competição, os jovens têm que mostrar suas habilidades técnicas e pessoais por meio das avaliações elaboradas por professores do SENAI, com base nas qualificações exigidas pelo mercado de trabalho, alinhadas aos avanços tecnológicos. Os Institutos Federais participam dessas competições desde 2016.

Este artigo apresenta as percepções dos professores treinadores desses alunos em relação às Competições de Educação Profissional do SENAI-SP, por intermédio dos seus relatos, a partir da aplicação de pesquisa qualitativa exploratória.

\section{A EDUCAÇÃo PROFISSIONAL NO CENÁRIO BRASILEIRO}

O papel da Educação Profissional, no cumprimento dos objetivos da educação nacional, é se integrar aos diferentes níveis e modalidades de educação e às dimensões do trabalho, da ciência, e da tecnologia.

Cunha (2000) destaca que o ensino industrial, destinado à formação da força de trabalho voltada diretamente à produção, resulta da própria história da Educação Profissional no Brasil, pois o ramo industrial manufatureiro veio ocupar uma posição hegemônica sobre os demais, servindo até mesmo de modelo para o conjunto das políticas educacionais do país. O trabalho manual acabou sendo percebido em função da carência da educação geral. Segundo o autor, quando a preocupação é com a "Educação Popular", são focalizados programas e atividades extracurriculares, notadamente os de iniciativa de organizações não propriamente educativas.
A educação industrial desenvolve-se mediante processos sistemáticos e estritamente regulamentados, destinados a produzir uma formação padronizada, de resultados previsíveis e controláveis, em geral voltada para um grande número de jovens. De um modo geral, a educação industrial se desenvolve em ambientes especializados, como escolas e centros de formação profissional. Mesmo quando ocorre dentro de uma fábrica, ela possui essas características. Os pressupostos da educação industrial são os mesmos da produção fabril, isto é, a intensa divisão do trabalho, particularmente a separação entre a concepção, a gerência e a execução (CUNHA, 2000, p. 11).

Manfredi (2002) afirma que as relações entre trabalho e escola, por sua vez, expressam visões ambíguas e idealizadas. Por um lado, estão as representações que denotam negatividade, mediante a subestimação da importância da escola e a supervalorização da experiência, dos saberes adquiridos no mundo do trabalho. Por outro lado, estão as visões idealizadas que superestimam a importância da escola como veículo de formação profissional e de ingresso no mercado de trabalho, ainda que exista um divórcio entre o que é ensinado na instituição escolar e os desafios a serem enfrentados no mundo do trabalho.

Peterossi (2014) aponta que, por ser a Educação Profissional e Tecnológica uma experiência distinta do sistema educacional mais amplo, provoca sentimentos que vão do desconforto em debater o tema à busca de relações de continuidades e semelhanças que a associem a esse sistema.

O fato é que está deixando de ter um lugar marginal no debate educacional, para incorporar-se a ele. Está deixando de ser uma educação pensada para uma sociedade fabril

1 http://www.sp.senai.br/ 
e, portanto, caracterizada como um bem cultural relativo a posições sociais menos privilegiadas, para ser considerada um bem econômico não só pelos indivíduos diretamente, mas pela sociedade em geral. Por sua relação com o saber tecnológico, passou a ser tratada como um investimento econômico estratégico e não mais como um dos fatores determinantes das relações de produção (PETEROSSI, 2014, p. 5).

Segundo a mesma autora, à medida que a sociedade se torna mais complexa e mais integrada pelo avanço das novas tecnologias, o mercado de trabalho se torna cada vez mais diferenciado e mais sujeito a mudanças, e, por conseguinte, mais se diversificam as expectativas sobre os profissionais que demanda. As empresas buscam qualificar seus profissionais preparando-os para um mundo cada vez mais competitivo, em que a educação, o treinamento e a inovação são fatores essenciais para o sucesso continuado das pessoas, organizações e países (PETEROSSI, 2014).

Weinberg (2014) destaca que as novas práticas de produção, comercialização e consumo de bens e serviços, a cooperação e competição entre os agentes, assim como, a circulação e a valorização do capital, são aspectos econômicos e sociais que interferem diretamente na formação dos profissionais e nos novos saberes e competências que devem demonstrar para uso das informações e conhecimento dos processos organizacionais. $\mathrm{O}$ desenvolvimento, a difusão e a convergência das tecnologias da informação e comunicação são vistos como centrais na conformação dessa nova dinâmica técnico-econômica.

De acordo com esses autores, a Educação Profissional, ao longo de sua história, manteve certos traços, mas também se aprofundou e diversificou ao redor de uma identidade única, que a diferencia como um esforço educativo nacional. A permanente geração de novos espaços de diálogo social, a participa- ção dos atores e a contínua busca de acompanhar as demandas dos setores produtivos e sociais fizeram que a Educação Profissional institucionalizada fosse reconhecida como uma das modalidades educacionais que respondem com maior qualidade, relevância e eficiência aos processos de inovação, mudança tecnológica e integração social.

Portanto, a Educação Profissional não pode ser considerada como coadjuvante de educação, embora haja a necessidade de promover seu desenvolvimento contínuo ante os desafios da competitividade econômica e das transformações sociais. Ainda mais, há uma real necessidade em transformar ou aumentar a atratividade na Educação Profissional, de modo a receber mais procura, e auxiliar no preparo de futuros profissionais para atender às demandas do mercado de trabalho, contribuindo assim para o desenvolvimento econômico do país.

\section{COMPETIÇÕES COMO INSTRUMENTO DE AVALIAÇÃO EM EDUCAÇÃO PROFISSIONAL}

A Educação Profissional, ainda que seja considerada por alguns como uma ação ligada diretamente à formação para atender às demandas do mercado de trabalho, tem a condição de ampliar sua ação e discussão para todas as situações que envolvam as transformações sociais e econômicas.

Analisando sob o tema das competições de educação profissional, cenário deste artigo, observa-se que, sob a perspectiva do SENAI, as competições podem ser consideradas um dos instrumentos de avaliação interna e externa à instituição, e também como um importante recurso para a projeção de marca institucional.

É importante lembrar que a avaliação tem caráter formativo e contribui para o aperfeiçoamento dos agentes da comunidade escolar e da instituição educacional. Como resultado, sedimenta-se a cultura da avaliação, que possibilita à instituição manter uma consciência atualizada sobre sua missão e acerca das finalidades escolar e social. 
Perrenoud (1999) declara que avaliar é criar hierarquias de excelência que possibilitarão certificações antes mesmo de entrar para o mercado de trabalho e que podem facilitar com frequência a contratação desse profissional.

Boruchovitch e Souza (2009) indicam que, em âmbito educacional, a avaliação pode ser considerada como uma forma de ajuizamento da qualidade do aluno ou futuro profissional em formação.

Para Dias Sobrinho (2010), a avaliação é a principal ferramenta de mudança de uma organização, uma vez que possibilita a implementação de reformas educacionais; permite mudanças em currículos, metodologias de ensino, conceitos e práticas de formação; incentiva a busca por processos mais modernos na gestão, estruturas de poder e modelos institucionais; promove configurações do sistema educativo; auxilia na definição de políticas e prioridades de pesquisa; e promove o desenvolvimento de conceitos sobre pertinência e responsabilidade social. O autor destaca que, obviamente, sempre haverá contradições e imperfeições num sistema de avaliação, pois se trata de um fenômeno social e de construção histórica.

Segundo Silveira (2014), mesmo com sistemas de avaliação já amadurecidos e sistematicamente implementados, as avaliações de larga escala resultam em indicadores de qualidade na educação. O Índice Brasileiro da Educação Básica (IDEB) é o indicador educacional que vem direcionando as políticas educacionais brasileiras na esfera federal e também estadual.

Entende-se também que a classificação das instituições de ensino profissional em ranking, a partir do desempenho dos alunos, contribui para que futuros alunos a identifiquem como a instituição que gostariam de participar e um posicionamento dessas instituições como excelência no processo educativo.

\section{O PROFESSOR TREINADOR E O AMBIENTE DE PESQUISA}

Quando se pensa no processo das competições, sejam elas esportivas ou educacionais, e principalmente no sentido que este artigo se propõe apresentar, um fator preponderante e fundamental para o competidor lograr o seu objetivo é a ação de seu treinador.

O treinador é o professor que acompanha o participante e se responsabiliza por seu preparo para a competição, além de ser um dos especialistas que avaliarão a aplicação dos projetos-testes nas competições.

No âmbito do SENAI, o papel do docente é refletido ante um posicionamento da instituição aos desafios impostos pelas demandas que têm promovido mudanças no perfil profissional das ocupações. Ao se analisar a proposta de prática docente adotada pelo SENAI, o docente precisa romper com a visão tradicional de ensino focada na reprodução de conteúdo e na aprendizagem passiva do aluno, para assumir o papel de mediador de aprendizagens.

Na história da formação do SENAI, bem como, da expansão da formação profissional, a Revolução de 1930, que levou Getúlio Vargas à chefia do governo provisório, estabeleceu o início de uma nova era, na História do Brasil, só terminada, em 1945, com o fim da Era Vargas.

Cunha (2000) pontua que no intuito de padronizar o ensino de ofícios, o ministro da Educação do governo de Getúlio Vargas organizou uma comissão para elaborar o projeto das diretrizes do ensino industrial em todo o país, abrangendo as escolas mantidas pelo poder público e pelos particulares. Em fins de 1941, a comissão concluiu o anteprojeto de lei orgânica do ensino industrial que foi submetido ao presidente da República, em princípios de janeiro de 1942, com o projeto que criava o SENAI.

Porém, o decreto-lei 4.048, de 22 de janeiro de 1942, que instituiu e normatizou a criação do SENAI, foi promulgado uma semana antes do decreto-lei 4.073, de 30 de ja- 
neiro de 1942, que instituía a lei orgânica do ensino industrial, que trouxe, como principal inovação, o deslocamento de todo o ensino profissional para o grau médio, passando o ensino primário a ter conteúdo exclusivamente geral. Esse deslocamento permitia que a própria escola selecionasse os alunos mais "educáveis" em virtude de sua origem social e cultural, segundo Cunha (2000).

No que tange à esfera institucional e política, visto pela ótica do poder institucional e da gestão dos recursos, o SENAI é uma instituição privada, dirigida pela Confederação Nacional da Indústria (CNI) e as federações estaduais dos sindicatos patronais, que têm a responsabilidade de escolherem seus diretores e determinarem a política a ser seguida. Na composição do Conselho Nacional e Regional, a participação mínima do Estado pode ser observada da seguinte maneira: ao lado dos presidentes de federações ou dos sindicatos patronais estão dois representantes do governo, sendo um do Ministério da Educação e outro do Ministério do Trabalho.

No que diz respeito ao SENAI SÃO PAULO (SENAI-SP), objeto deste estudo, observa-se que, em 2017, a rede compreendia 165 escolas profissionais no Estado de São Paulo, sendo 91 escolas fixas, 74 escolas móveis, com mais de 75 anos de existência, com uma produção de 1.000.639 matrículas realizadas no ano de 2015.

A missão do SENAI, declarada no documento Perfil Institucional do SENAI-SP, é promover a Educação Profissional e Tecnológica, a inovação e a transferência de tecnologias industriais, contribuindo para elevar a competitividade da indústria brasileira. O mesmo documento aponta que o Departamento Regional de São Paulo (DR-SP) foi o primeiro a ser implantado no país, em 1942.

O SENAI-SP se posiciona como provedor de soluções educacionais e tecnológicas, alinhadas às políticas que trabalham pela competitividade da indústria brasileira. Nos últimos anos, acompanhando o desenvolvimento das indústrias paulistas, que se modernizaram e conquistaram nichos importan- tes no mercado mundial, o SENAI-SP investiu continuamente em atualização tecnológica e expansão da rede de escolas.

Sua visão estratégica é ser líder e referência nacional em educação profissional e tecnológica e reconhecido como indutor da inovação e da transferência de tecnologias para a Indústria Brasileira, apoiando o desenvolvimento econômico sustentado.

\section{A pesquisa e Seus resultados}

Sob o aspecto institucional, conforme documento elaborado pelo SENAI, as competições de formação profissional têm o propósito de colaborar na melhoria da qualidade do ensino profissional, levando em consideração, como fator importante, a intensa participação das escolas, e mais especificamente, do seu corpo docente e discente.

Além de desenvolver o aluno para o mercado de trabalho, as Competições de Educação Profissional devem propiciar pontos de melhoria no processo educacional, como a revisão e aperfeiçoamento de material didático, o aperfeiçoamento de práticas pedagógicas no processo de ensino-aprendizagem, a atualização e formação continuada de docentes e a inserção de inovações tecnológicas no processo educacional.

Segundo a página da web do SENAI, Departamento Nacional, a Olimpíada do Conhecimento é a maior competição de educação profissional das Américas. O torneio, promovido a cada dois anos, reúne estudantes de cursos técnicos e de formação profissional do SENAI. Em função disso, foi o locus escolhido para esta pesquisa.

O objetivo desta pesquisa, conforme exibido, é apresentar as experiências que os professores treinadores dos ex-competidores tiveram ao longo dos processos de participação em competições de Educação Profissional.

Esta pesquisa tem um enfoque qualitativo e, de acordo com Sampieri, Collado e Lucio (2013), esse tipo de pesquisa proporciona profundidade aos dados, dispersão, riqueza 
interpretativa, contextualização do ambiente, detalhes e experiências únicas.

O método de pesquisa utilizado foi documental por meio da análise de relatórios do SENAI-SP e uma pesquisa de campo com professores especialistas.

O instrumento de pesquisa aplicado foi um questionário para os professores treinadores contendo perguntas objetivas e abertas, a fim de que os respondentes relatassem sua participação nos processos de competições de educação profissional. O questionário foi aplicado de janeiro a maio de 2017 e foi uma adaptação do instrumento usado na pesquisa internacional realizada pela Universidade de Tampere, Finlândia, a RMIT University, Austrália, e a Universidade de Oxford, Inglaterra, por ser um instrumento já utilizado e consolidado em várias competições.

Foram selecionados 154 professores do SENAI-SP que participaram dos processos de competições anteriores a 2017, tendo-se remetido o link do questionário em $1^{\circ}$. de fevereiro de 2017 e obtido o retorno de 46 professores (30\%) até 11 de maio de 2017.

Para o levantamento dos resultados obtidos a partir da pesquisa realizada até o encerramento do período em que o link ficou disponível (11 de maio de 2017), todas as respostas foram coletadas e convertidas em formato Excel, a fim de se proceder com o tratamento dos dados.

Importante esclarecer que o processo das competições no SENAI é desenvolvido em quatro níveis:

O primeiro nível é a seleção escolar, que busca identificar os competidores (alunos ou ex-alunos) e treinadores/avaliadores (professores) que representarão a Unidade na fase regional (estadual). O processo de seleção é de responsabilidade da direção escolar, que pode escolher o melhor aluno levando em consideração a proposta pedagógica, a análise de histórico escolar ou a escolha por meio de aplicação de testes. Os alunos que se destacam serão os representantes da escola, na etapa estadual;

O segundo nível é a fase regional ou estadual, que contempla todas as escolas do
SENAI, do Departamento Regional do respectivo Estado, onde as escolas competem entre si em diferentes modalidades tecnológicas, e a escola que se sagrar campeã representará o Estado na competição em nível nacional. Nesse nível, tem-se o exemplo da São Paulo Skills, competição organizada pelo SENAI-SP a fim de escolher os seus representantes para a Olimpíada do Conhecimento;

O terceiro nível é a fase nacional, a Olimpíada do Conhecimento, que contempla todos os Departamentos Regionais, sendo um por Estado. Na Olimpíada do Conhecimento, o Departamento Regional que se sagrar campeão, de acordo com sua modalidade, será o representante do Brasil na competição em nível internacional, que é o último nível.

O quarto nível é a fase internacional, onde o SENAI é o representante do Brasil nas competições de educação profissional competindo com Instituições de Educação Profissional de outros países. Esse nível é de responsabilidade da WorldSkills International, que é uma instituição sem fins lucrativos, cujo propósito é a promoção de benefícios e a necessidade de profissionais qualificados por meio de projetos comunitários de base, competições de habilidades e intercâmbio de conhecimento.

Nas competições, sejam elas em nível estadual ou nacional, o SENAI é responsável pela implantação e adequação das instalações dos ambientes de competição, equipamentos, de acordo com o Descritivo Técnico e Documentos de Infraestrutura. A organização da competição deve preparar um programa geral providenciando todos os trâmites logísticos de seus competidores e treinadores, bem como, o de recepção do público em geral.

A análise de dados inicia-se a partir das respostas obtidas com os treinadores, por meio de um levantamento demográfico. A Tabela 1 apresenta o número de respondentes. A pesquisa não abordou a questão de gênero e os treinadores que respondiam à pesquisa puderam se identificar. Ao verificar os nomes dos treinadores, foi observado uma participação maior de treinadores do sexo masculino 
( $91 \%$ ) do que treinadores do sexo feminino (9\%). Isso, provavelmente, ocorre por causa da tendência de o SENAI-SP atuar com professores que vieram do mercado que, poucos anos atrás, dava preferência ao trabalho masculino em detrimento do feminino.

Tabela 1 - Levantamento demográfico para verificar o perfil do treinador.

\begin{tabular}{l|l|l|l|l|l|l}
\hline Amostra & $\begin{array}{l}\text { Total de } \\
\text { Respostas }\end{array}$ & $\begin{array}{l}\text { Percen- } \\
\text { tual }\end{array}$ & $\begin{array}{l}\text { Treinadores } \\
\text { do sexo } \\
\text { masculino }\end{array}$ & Percentual & $\begin{array}{l}\text { Treinadores do } \\
\text { sexo feminino }\end{array}$ & Percentual \\
\hline 154 & 46 & $30 \%$ & 42 & $91 \%$ & 04 & $9 \%$ \\
\hline
\end{tabular}

Fonte: Elaborado pelos autores.

A Tabela 2 apresenta a média da faixa etária dos treinadores, o que nos aponta para um público exclusivamente jovem, de aproximadamente 38 anos e 11 meses de idade, em fase de desenvolvimento de sua formação e consequente carreira profissional.

Tabela 2 - Levantamento da faixa etária dos treinadores.

\begin{tabular}{l|l|l}
\hline $\begin{array}{l}\text { Faixa etária média dos } \\
\text { treinadores }\end{array}$ & $\begin{array}{l}\text { Faixa etária média dos } \\
\text { treinadores do sexo masculino }\end{array}$ & $\begin{array}{l}\text { Faixa etária média dos } \\
\text { treinadores do sexo } \\
\text { feminino }\end{array}$ \\
\hline 38 anos e 11 meses & 38 anos e 10 meses & 39 anos e 4 meses \\
\hline
\end{tabular}

Fonte: Elaborado pelos autores.

A Tabela 3 apresenta a quantidade de vezes que os treinadores participaram das competições de Educação Profissional, como especialistas. A participação como especialista não está apenas na condição de ser um treinador, mas o especialista é o profissional que avalia o desempenho dos competidores durante a competição. As avaliações são objetivas e, em alguns casos, subjetivas, porém todas seguem os critérios estabelecidos nos descritivos técnicos e projetos-teste.

Tabela 3 - Quantidade de participações na competição estadual.

\begin{tabular}{l|l|l|l|l|l}
\hline $\begin{array}{l}\text { Participação } \\
\text { em 1 compe- } \\
\text { tição }\end{array}$ & $\begin{array}{l}\text { Participação } \\
\text { em 2 compe- } \\
\text { tições }\end{array}$ & $\begin{array}{l}\text { Participação } \\
\text { em 3 compe- } \\
\text { tições }\end{array}$ & $\begin{array}{l}\text { Participação } \\
\text { em 4 compe- } \\
\text { tições }\end{array}$ & $\begin{array}{l}\text { Participação } \\
\text { em 5 compe- } \\
\text { tições }\end{array}$ & $\begin{array}{l}\text { Participação } \\
\text { de 6 a 10 } \\
\text { competições }\end{array}$ \\
\hline 9 & 9 & 12 & 6 & 7 & 3 \\
\hline $20 \%$ & $20 \%$ & $26 \%$ & $13 \%$ & $15 \%$ & $6 \%$ \\
\hline
\end{tabular}

Fonte: Elaborado pelos autores.

Os resultados apresentados pela Tabela 3 mostram que os treinadores vêm mantendo certo envolvimento com as competições em nível estadual. É possível observar que 12 treinadores (26\%) têm experiência em três participações em competições em nível estadual e pelo menos três treinadores (6\%) já tiveram a experiência em participar de seis a dez competições, o que significa pelo menos 12 anos de experiência na preparação de competidores (alunos/ex-alunos) em competições de Educação Profissional. 
A Tabela 4 apresenta os resultados das participações dos treinadores nas competições em nível nacional.

Tabela 4 - Quantidade de participações na competição nacional.

\begin{tabular}{l|l|l|l|l|l|l}
\hline $\begin{array}{l}\text { Participação } \\
\text { em 1 } \\
\text { competição }\end{array}$ & $\begin{array}{l}\text { Participação } \\
\text { em 2 } \\
\text { competições }\end{array}$ & $\begin{array}{l}\text { Participação } \\
\text { em 3 } \\
\text { competições }\end{array}$ & $\begin{array}{l}\text { Participação } \\
\text { em 4 } \\
\text { competições }\end{array}$ & $\begin{array}{l}\text { Participação } \\
\text { em 5 } \\
\text { competições }\end{array}$ & $\begin{array}{l}\text { Participação } \\
\text { de 6 a 10 } \\
\text { competições }\end{array}$ & $\begin{array}{l}\text { Nunca } \\
\text { participou }\end{array}$ \\
\hline 13 & 9 & 4 & 3 & 0 & 1 & 16 \\
\hline $29 \%$ & $20 \%$ & $9 \%$ & $6 \%$ & $0 \%$ & $2 \%$ & $35 \%$ \\
\hline
\end{tabular}

Fonte: Elaborado pelos autores.

Conforme demonstram os resultados na Tabela 4, 13 treinadores (29\%) responderam que já tiveram a oportunidade de estar envolvidos na competição em nível nacional, o que quer dizer que esses profissionais representavam o SENAI-SP na competição nacional. Significa, também, que havia um competidor participando e representando o SENAI-SP na competição nacional. Os resultados apontam também que um treinador teve a oportunidade de representar o SENAI-SP com o seu competidor em pelo menos seis ocorrências na competição nacional.

A Tabela 5 apresenta a quantidade de vezes que os treinadores respondentes participaram como especialistas na competição internacional.

Tabela 5 - Quantidade de participações na competição internacional.

\begin{tabular}{l|l|l|l}
\hline $\begin{array}{l}\text { Participação em } \\
1 \text { competição }\end{array}$ & $\begin{array}{l}\text { Participação em } 2 \\
\text { competições }\end{array}$ & $\begin{array}{l}\text { Participação em } \\
3 \text { competições }\end{array}$ & Nunca participou \\
\hline 5 & 3 & 1 & 37 \\
\hline $11 \%$ & $7 \%$ & $2 \%$ & $80 \%$ \\
\hline
\end{tabular}

Fonte: Elaborado pelos autores.

Conforme demonstra a Tabela 5 , dos treinadores que responderam à pesquisa, cinco treinadores (11\%) foram especialistas na competição internacional, e tiveram a oportunidade de, com o seu competidor, representarem o SENAI-SP e o Brasil. A tabela demonstra também que $80 \%$ dos treinadores que responderam à pesquisa não representaram o SENAI-SP na competição internacional. Para se tornar um especialista e representar o Brasil, em nível internacional, requer que o desempenho do treinador seja excelente e, geralmente, o desempenho do treinador é observado a partir do desempenho do competidor.

Outro levantamento feito junto aos treinadores foi a verificação de quantos treinadores foram competidores e em quais competições (Estadual, Nacional e Internacional).

A Tabela 6 apresenta a participação dos treinadores como competidores.

Tabela 6 - Quantidade de participações nas competições como competidor.

\begin{tabular}{l|l|l|l}
\hline $\begin{array}{l}\text { Participou } \\
\text { como competidor? }\end{array}$ & Competição Estadual & Competição Nacional & $\begin{array}{l}\text { Competição Internacio- } \\
\text { nal }\end{array}$ \\
\hline Sim & 19 & 10 & 3 \\
\hline Percentual & $41 \%$ & $22 \%$ & $7 \%$ \\
\hline Não & 27 & 36 & 43 \\
\hline Percentual & $59 \%$ & $78 \%$ & $93 \%$ \\
\hline
\end{tabular}

Fonte: Elaborado pelos autores. 
Conforme mostram os resultados na Tabela 6, 19 treinadores (41\%) tiveram a possibilidade de participar na competição estadual como competidor, dez treinadores (22\%) participaram na competição nacional e três competidores (7\%) tiveram a experiência em participar da competição internacional.

Os professores que participaram das competições como competidores, em geral, têm suas atividades para o treinamento de novos competidores, mantendo-se sempre envolvidos com as ações relacionadas às competições.

Foi identificado também junto aos treinadores algumas questões que eles pudessem mencionar referente à sua experiência em participar da preparação para as competições.

A Tabela 7 apresenta o que os treinadores julgaram ser mais importante com relação à sua experiência em participar da preparação para as competições.

Tabela 7 - Fator mais importante em participar das competições - treinadores.

\begin{tabular}{l|l|l}
\hline Resposta dos Treinadores & $N^{\circ}$. de Respostas & Frequência \\
\hline Conhecer pessoas novas na minha profissão & 5 & $11 \%$ \\
\hline Apoiar os competidores & 39 & $83 \%$ \\
\hline Incrementar minha carreira & 3 & $6 \%$ \\
\hline Não se aplica & 0 & $0 \%$ \\
\hline
\end{tabular}

Fonte: Elaborado pelos autores.

Conforme apontam os resultados apresentados na Tabela 7, para 39 treinadores (83\%) o fator mais importante em estar envolvido com as competições é o fato de apoiar seus competidores.

Outro ponto de destaque dos treinadores está no quesito do desenvolvimento da sua experiência com relação à participação nas competições. Segundo os treinadores, o fato de estarem envolvidos com as competições permite que eles desenvolvam relacionamento com colegas de profissão, se mantenham atualizados com os desenvolvimentos na atividade/profissão, enxerguem novas possiblidades nas suas carreiras, acompanhem o sucesso dos competidores, estabeleçam comparativos entre os níveis de formação e o desenvolvimento de suas habilidades como especialistas.

A Tabela 8 demonstra como os profissionais informaram o desenvolvimento de sua experiência nas competições. Os respondentes podiam escolher quantas opções desejassem.

Tabela 8 - Resultados acerca de como se desenvolveu a experiência - treinadores.

\begin{tabular}{l|l|l}
\hline Resposta dos Treinadores & $\begin{array}{l}\mathrm{N}^{\circ} \text {. de } \\
\text { Respostas }\end{array}$ & Frequência \\
\hline Networking com colegas de outras unidades/colegas de profissão & 41 & $91 \%$ \\
\hline Ver pessoas jovens darem o melhor de si & 37 & $82 \%$ \\
\hline $\begin{array}{l}\text { Mantendo-se atualizado com os desenvolvimentos na minha ati- } \\
\text { vidade/profissão }\end{array}$ & 44 & $98 \%$ \\
\hline Enxergando novas possibilidades na carreira & 31 & $69 \%$ \\
\hline $\begin{array}{l}\text { Fazer comparações relativas entre os níveis de formação e os pa- } \\
\text { drões internacionais }\end{array}$ & 38 & $84 \%$ \\
\hline Desenvolver minhas habilidades como especialista & 42 & \\
\hline
\end{tabular}

Fonte: Elaborado pelos autores. 
Conforme demonstra a Tabela 8, entre os 46 respondentes, 44 treinadores (98\%) entendem que a experiência em participar das competições permite que eles se mantenham atualizados com os desenvolvimentos na sua atividade/profissão, 41 treinadores (91\%) entendem que permite estabelecer uma rede de contatos com colegas de profissão, 42 treinadores (93\%) entendem que as competições permitem o desenvolvimento das habilidades como especialista. Demonstra, também, que 31 treinadores (69\%) enxergam novas possiblidades nas suas carreiras, pelo fato de estarem envolvidos com as competições, o que reforça os resultados apontados na Tabela 7.

A pesquisa permitiu aos treinadores relatarem, por meio de depoimentos, sobre o que significava para eles estarem envolvidos com as competições, como especialistas. No questionário proposto, havia um espaço para que eles pudessem gerar esse relato. A questão proposta foi:

Você foi solicitado para falar com um grupo de membros de sua atividade/profissão sobre o que significa estar envolvido com as competições como Especialista. O que você diria a eles, com base na sua própria experiência com competições de Educação Profissional?

De forma a sistematizar a análise das respostas dos treinadores, foram estabelecidas sete categorias para a classificação das respostas, com base na frequência dos vocabulários; utilizou-se o software Microsoft Excel para proceder a análise dos dados, parametrizado segundo as categorias:

- Conhecimento, Aperfeiçoamento, Treinamento, Treinar, Habilidades, Técnicas, Competências, Atitudes, Aprender, Aprendizado, Aprendizagem;
- Crescimento Profissional, Desenvolvimento Profissional, Realização Profissional, Profissão;

- Crescimento Pessoal, Desenvolvimento Pessoal, Realização Pessoal, Satisfação, Orgulho;

- Dedicação, Vontade, Força de Vontade, Esforço, Postura, Envolvimento, Desafio, Dificuldade, Superação, Sucesso;

- Responsabilidade, Compromisso, Comprometimento, Planejamento, Planejar, Plano, Organização, Organizar, Estratégia;

- Experiência única, Enriquecedora, Ótima, Oportunidade, Excelente;

- Trabalho em equipe, Comunicação, Contatos, Troca de Conhecimentos, Relacionamento, Compartilhamento, Disseminar.

A categoria 7 foi percebida nos relatos dos treinadores, uma vez que aos treinadores cabe o papel de ser docente, e cabe ao docente ser um mediador dos processos de troca de conhecimentos, de estimular o trabalho em equipe, de compartilhar.

Importante destacar que todos os 46 respondentes aceitaram relatar suas experiências em ter participado das competições de Educação Profissional, apesar de ser opcional.

A Tabela 9 aponta quantos treinadores, ao relatarem suas experiências em participar das competições como especialistas, mencionaram o termo "conhecimento" como vocábulo mais frequente. A categoria 1 foi utilizada para a classificação dos dados com os termos: Conhecimento, Aperfeiçoamento, Treinamento, Treinar, Habilidades, Técnicas, Competências, Atitudes, Aprender, Aprendizado, Aprendizagem. 
Tabela 9 - Relato dos treinadores - Categoria 1.

\begin{tabular}{l|l|l}
\hline Descrição & $\mathrm{N}^{\circ}$. de respostas & Frequência \\
\hline Total de treinadores & 46 & $100 \%$ \\
\hline Treinadores que mencionaram os conteúdos da categoria 1 & 27 & $59 \%$ \\
\hline Treinadores que não mencionaram os conteúdos da categoria 1 & 19 & $41 \%$ \\
\hline
\end{tabular}

Fonte: Elaborado pelos autores.

Os resultados demonstrados pela Tabela 9 indicam que para 27 treinadores (59\%) estar envolvido nas competições de Educação Profissional como especialistas é uma oportunidade de adquirir novos conhecimentos, poder se aperfeiçoar, aprender novas técnicas.

A Tabela 10 indica os resultados de quantos treinadores, ao darem o relato de seu envolvimento como especialista nas competições, utilizaram o termo "profissional" como o vocábulo mais presente em seus depoimentos. A categoria 2 foi utilizada para a classificação dos dados, contendo os termos: Crescimento Profissional, Desenvolvimento Profissional, Profissão.

Tabela 10 - Relato dos treinadores - Categoria 2.

\begin{tabular}{l|l|l}
\hline Descrição & No. de respostas $^{\circ}$ & Frequência \\
\hline Total de treinadores & 46 & $100 \%$ \\
\hline Treinadores que mencionaram os conteúdos da categoria 2 & 31 & $67 \%$ \\
\hline Treinadores que não mencionaram os conteúdos da categoria 2 & 15 & $33 \%$ \\
\hline
\end{tabular}

Fonte: Elaborado pelos autores.

De acordo com os resultados apresentados pela Tabela 10, 31 treinadores (67\%) entendem que o envolvimento nas competições de Educação Profissional acarreta no desenvolvimento profissional, no sentido de realização profissional.

A Tabela 11 apresenta os resultados de quantos treinadores relataram que o envolvimento nas competições de Educação Profissional como especialistas mencionaram o termo "pessoal" como vocábulo mais predominante. A categoria 3 foi utilizada para a classificação dos dados contendo os termos: Crescimento Pessoal, Desenvolvimento Pessoal, Realização Pessoal, Satisfação, Orgulho.

Tabela 11 - Relato dos treinadores - Categoria 3.

\begin{tabular}{l|l|l}
\hline Descrição & $N^{\circ}$. de respostas & Frequência \\
\hline Total de treinadores & 46 & $100 \%$ \\
\hline Treinadores que mencionaram os conteúdos da categoria 3 & 20 & $43 \%$ \\
\hline Treinadores que não mencionaram os conteúdos da categoria 3 & 26 & $57 \%$ \\
\hline
\end{tabular}

Fonte: Elaborado pelos autores.

Os resultados demonstrados pela Tabela 11 indicam que 20 treinadores (43\%) entendem que o envolvimento como especialistas na competição é uma satisfação pessoal, é uma realização para suas vidas, sentem orgulho de participar das competições. Esse resultado vai ao encontro do resultado apresentado pela Tabela 6, em que 19 treinadores (41\%), entre os 46 
treinadores que participaram da pesquisa, já foram competidores na fase estadual. Importante destacar que mais da metade dos respondentes (57\%) não mencionou os termos da Categoria 3.

A Tabela 12 mostra a quantidade de treinadores que, ao darem seu relato sobre o envolvimento nas competições, mencionaram como termos mais frequentes "a importância da dedicação, esforço, força de vontade, a superação de desafios, as dificuldades apresentadas". A categoria 4 foi utilizada para a classificação dos dados, contendo os termos: Dedicação, Vontade, Força de Vontade, Esforço, Postura, Envolvimento, Desafio, Dificuldade, Superação, Sucesso.

Tabela 12 - Relato dos treinadores - Categoria 4.

\begin{tabular}{l|l|l}
\hline Descrição & No. de respostas $^{\circ}$ & Frequência \\
\hline Total de treinadores & 46 & $100 \%$ \\
\hline Treinadores que mencionaram os conteúdos da categoria 4 & 28 & $61 \%$ \\
\hline Treinadores que não mencionaram os conteúdos da categoria 4 & 18 & $39 \%$ \\
\hline
\end{tabular}

Fonte: Elaborado pelos autores.

Conforme demonstrado pela Tabela 12, 28 treinadores (61\%) reconhecem que para estar envolvido com as competições de Educação Profissional deve haver dedicação, força de vontade, ser esforçado, por ser uma experiência que envolve dificuldades e desafios a serem superados.

A Tabela 13 demonstra os resultados obtidos nos relatos dos treinadores sobre o envolvimento nas competições como especialistas; os termos mais frequentes foram os vocábulos “responsabilidade”, “comprometimento”, “planejamento”, “estratégia” e “organização”. A categoria 5 foi adotada fazendo a classificação dos depoimentos contendo: Responsabilidade, Compromisso, Comprometimento, Planejamento, Planejar, Plano, Organização, Organizar, Estratégia.

Tabela 13 - Relato dos treinadores - Categoria 5.

\begin{tabular}{l|l|l}
\hline Descrição & $\mathrm{N}^{\circ}$. de respostas & Frequência \\
\hline Total de treinadores & 46 & $100 \%$ \\
\hline Treinadores que mencionaram os conteúdos da categoria 5 & 8 & $17 \%$ \\
\hline Treinadores que não mencionaram os conteúdos da categoria 5 & 38 & $83 \%$ \\
\hline
\end{tabular}

Fonte: Elaborado pelos autores.

Os resultados demonstrados pela Tabela 13 apontam que apenas oito treinadores (17\%) disseram que estar envolvido nas competições requer responsabilidades, comprometimento, saber planejar. Embora os resultados apresentem uma parcela pequena de treinadores que mencionaram os termos da categoria 5, perante as outras categorias apresentadas, está implícita na participação das competições para os especialistas a questão da responsabilidade, do comprometimento nas ações que envolvem ser um especialista.

A Tabela 14 apresenta a quantidade de treinadores que relataram que o envolvimento nas competições como especialistas é uma experiência única e enriquecedora nas suas vidas. O vocábulo mais frequente foi "experiência única". A categoria 6 foi utilizada para a classificação dos dados, contendo os termos: Experiência única, Enriquecedora, Ótima, Oportunidade, Excelente. 
Tabela 14 - Relato dos treinadores - Categoria 6.

\begin{tabular}{l|l|l}
\hline Descrição & $\mathrm{N}^{\circ}$. de respostas & Frequência \\
\hline Total de treinadores & 46 & $100 \%$ \\
\hline Treinadores que mencionaram os conteúdos da categoria 6 & 21 & $46 \%$ \\
\hline Treinadores que não mencionaram os conteúdos da categoria 6 & 25 & $54 \%$ \\
\hline
\end{tabular}

Fonte: Elaborado pelos autores.

Conforme apontam os resultados na Tabela 14, 21 treinadores (46\%) relataram que estar envolvido nas competições de Educação Profissional é uma experiência única e enriquecedora para eles, pois são experiências transformadoras nas suas vidas. Segundo os relatos, a participação nas competições permite agregar todos os pontos que já foram mencionados.

A Tabela 15 apresenta o número de treinadores que, ao relatarem seu envolvimento com as competições de Educação Profissional entendiam que, além de considerar todos os aspectos técnicos, pessoais e profissionais, estavam relacionados às competições os termos: o trabalho em equipe, as habilidades de comunicação, a troca de conhecimentos, a construção de redes de relacionamento, o ato de compartilhar o conhecimento. A categoria 7 foi adotada para classificar os dados contendo: Trabalho em equipe, Comunicação, Contatos, Troca de Conhecimentos, Relacionamento, Compartilhamento, Disseminar.

Tabela 15 - Relato dos treinadores - Categoria 7.

\begin{tabular}{l|l|l}
\hline Descrição & $N^{\circ}$. de respostas & Frequência \\
\hline Total de treinadores & 46 & $100 \%$ \\
Treinadores que mencionaram os conteúdos da categoria 7 & 11 & $24 \%$ \\
Treinadores que não mencionaram os conteúdos da categoria 7 & 35 & $76 \%$ \\
\hline
\end{tabular}

Fonte: Elaborado pelos autores.

Os resultados apresentados na Tabela 15 indicam que 11 treinadores (24\%), ao darem seus relatos, apontaram que seu envolvimento na competição dependia da realização do trabalho em equipe, que há uma necessidade de estabelecer a comunicação entre os pares, bem como, promover a troca de conhecimentos.

Pôde-se observar que os treinadores têm uma visão muito abrangente da significância de participar de uma competição de Educação Profissional, o que pode ser constatado a partir do relato dado por um treinador:

A participação como expert exige uma postura profissional mais ágil e voltada a resultado, o que implica em apurar o senso crítico, as capacida- des de avaliação, comprometimento, previsibilidade, administração de conflitos, negociação, aprendizagem e planejamento estratégico. E tudo isso é multiplicado quando é transferido para a sala de aula e para a vida (RELATO DO EXPERT).

Percebe-se que a competição para os treinadores tem um sentido de aprimoramento de suas práticas pedagógicas, de desenvolvimento profissional e pessoal, de avaliar situações de aprendizagem agregando valor à atividade docente ao transferir isso aos demais alunos.

Os resultados apresentados denotam que os especialistas (professores) veem nas competições de Educação Profissional uma 
oportunidade de aprimorar seus conhecimentos técnicos e se manterem atualizados e em contínuo desenvolvimento profissional. Denotam, também, a oportunidade que os profissionais têm de desenvolver trabalhos em equipe e trocam experiências e conhecimento por meio dessa experiência.

\section{CONSIDERAÇões FINAIS}

Cabe à Educação Profissional no Brasil desempenhar um importante papel na transformação social e econômica da nação. O papel da Educação Profissional consiste na formação para o mundo do trabalho, ou seja, ela forma profissionais com habilidades para utilizar os conhecimentos de modo inovador ao aplicá-los e difundi-los no mundo do trabalho.

Nesse sentido, Instituições de Educação Profissional como o SENAI promovem alternativas que servem de instrumentos de avaliação institucional, demonstrando o investimento que fazem no processo de formação de seus alunos, os futuros profissionais que o mercado de trabalho absorverá. No caso do SENAI, uma das alternativas é por meio das Competições de Educação Profissional, como exemplo da SP Skills em âmbito do Estado de São Paulo, a Olimpíada do Conhecimento em âmbito nacional, e a WorldSkills Competition em âmbito internacional.

Do ponto de vista institucional, as competições são um dos instrumentos que visam avaliar o sistema de Educação Profissional do SENAI e possibilitam a projeção da marca da instituição em nível nacional e internacional. As competições, além de servirem como instrumentos de avaliação institucional, possibilitam à instituição a atualização de seus currículos e metodologias de formação, promovem o aperfeiçoamento e atualização técnica de seus docentes, a atualização de suas máquinas e equipamentos em função da parceria construída com as empresas, e criam uma oportunidade de tornar a Educação Profissional mais atrativa aos jovens em busca de formação.

Para tanto, esta pesquisa atingiu seu objetivo ao apresentar os relatos dos professores treinadores do SENAI-SP que declararam o que vivenciaram no processo de participação das competições. Os resultados obtidos a partir da pesquisa abrem oportunidades para a ampliação dos estudos no âmbito das competições como mecanismos de avaliação institucional para as instituições de educação profissional.

Conforme demonstrado pelos resultados a partir das pesquisas aplicadas aos treinadores, a competição é uma experiência única e marcante na vida de cada pessoa que esteve ou está envolvida com as competições. Ao treinador, a competição é uma maneira de se manter atualizado no seu campo de atuação profissional, aperfeiçoar seus conhecimentos técnicos, poder desenvolver suas capacidades de trabalho em equipe e construção de uma rede de relacionamento, por meio da troca de experiências e compartilhamento de conhecimento entre todos os envolvidos, sejam outros especialistas, sejam competidores de outras escolas, instituições ou outros países.

Para o competidor, foi uma maneira de aprimorar seus conhecimentos técnicos, desenvolver-se profissionalmente, tornando-se um profissional altamente qualificado para o mercado de trabalho competitivo.

Não se busca, neste artigo, o esgotamento do assunto em termos das competições de Educação Profissional, mas se procura ampliar os estudos de modo a contribuir para o estabelecimento de um instrumento de avaliação nacional da Educação Profissional no Brasil. Este trabalho permite ampliar o leque da discussão a respeito dos métodos avaliativos que as Instituições de Educação Profissional utilizam como argumento na busca pela excelência da Educação Profissional. 


\section{REFERÊNCIAS}

BORUCHOVITCH, E.; SOUZA, N. A. Avaliação da aprendizagem e motivação para aprender: tramas e entrelaços na formação de professores, 2009. Disponível em: <http://linkp03 nov. 2016.

BRASIL. Lei nº 4.048, de 22 de janeiro de 1942. Cria o Serviço Nacional de Aprendizagem dos Industriários (SENAI). Disponível em: http://www.planalto.gov.br/ccivil_03/decreto-lei/1937-1946/ Del4048.htm. Acesso em: 27 set. 2016.

CUNHA, L. A. O Ensino industrial manufatureiro no Brasil. Revista Brasileira de Educação, n. 14, mai./jun./jul./ago. 2000.

DIAS SOBRINHO, J. Avaliação e transformações da educação superior brasileira (1995-2009): do Provão ao SINAES. 2010. Disponível em: http://www.scielo.br/pdf/aval/v15n1/v15n1a11.pdf. Acesso em: 3 nov. 2016.

MANFREDI, S. M. Educação profissional no Brasil. São Paulo: Cortez, 2002.

PERRENOUD, P. Avaliação: da excelência à regulação das aprendizagens - entre duas lógicas. Rio Grande do Sul: Artmed, 1999.

PETEROSSI, H. G. Subsídios ao estudo da educação profissional e tecnológica. São Paulo: Centro Paula Souza, 2014.

SAMPIERI, R. H., COLLADO, C. F., LUCIO, M. P.B. Metodologia de Pesquisa, 5. ed. Porto Alegre: McGrawHill, 2013.

SILVEIRA R. C. O. PROVEI: Um programa de avaliação externa da educação profissional - SENAI - departamento regional de São Paulo, 2014. Disponível em: <http://www.anpae.org.br/ IBERO_AMERICANO_IV/GT3/GT3_Coimunicacao/RitadeCassiaOliveiradaSilveira_GT3_integral. pdf $>$. Acesso em: 15 de mar. 2017.

WEINBERG, P. D. Educação profissional: rompendo certezas, correndo barreiras. Rio de Janeiro: Boletim Técnico do SENAC, 2014.

\section{MARILIA Macorin de Azevedo}

Doutora em Engenharia pela Universidade de São Paulo (USP). Professora no Centro Estadual de Educação Tecnológica Paula Souza (CEETPS). marilia.azevedo@fatec.sp.gov.br

\section{Celi LANGHI}

Doutora em Psicologia Escolar e do Desenvolvimento Humano pela Universidade de São Paulo (USP). Professora no Centro Estadual de Educação Tecnológica Paula Souza (CEETPS). celi@ infolearning.com.br

\section{ANDERSON BARCELOS Rocha BRAGA}

Mestre em Gestão e Desenvolvimento da Educação Profissional pelo Centro Estadual de Educação Tecnológica Paula Souza (CEETPS). anderson.braga@sp.senai.br

Submetido em: 27-11-2018

Aceito em: 30-4-2019 